\title{
Aberrant expression of anaplastic lymphoma kinase in lung adenocarcinoma: Analysis of circulating free tumor RNA using one-step reverse transcription-polymerase chain reaction
}

\author{
ROSSELLA BRUNO ${ }^{1}$, MIRELLA GIORDANO ${ }^{1}$, RICCARDO GIANNINI ${ }^{1}$, GRETA ALİ ${ }^{2}$, \\ GIANFRANCO PUPPO ${ }^{3}$, ALESSANDRO RIBECHINI $^{4}$, ANTONIO CHELLA ${ }^{3}$ and GABRIELLA FONTANINI ${ }^{1,5}$ \\ ${ }^{1}$ Department of Surgical, Medical, Molecular Pathology and Critical Area, University of Pisa, I-56126 Pisa; \\ ${ }^{2}$ Unit of Pathological Anatomy; ${ }^{3}$ Unit of Pneumology; ${ }^{4}$ Endoscopic Section of Pneumology; \\ ${ }^{5}$ Program of Pleuro-Pulmonary Pathology, University Hospital of Pisa, I-56100 Pisa, Italy
}

Received February 10, 2016; Accepted June 2, 2016

DOI: $10.3892 / \mathrm{mmr} .2016 .5479$

\begin{abstract}
Lung adenocarcinoma patients harboring anaplastic lymphoma kinase (ALK) gene rearrangements respond well to approved ALK inhibitors. However, to date, limited evidence is available regarding whether using circulating free tumor mRNA to identify aberrant $A L K$ expression is possible, and its feasibility remains to be clearly addressed. The present study evaluated $A L K$ expression by a one-step reverse transcription-polymerase chain reaction (PCR) assay on the circulating free tumor mRNA from 12 lung adenocarcinoma patients. Additionally, the present study tested for $A L K$ rearrangements by fluorescence in situ hybridization (FISH) and immunohistochemistry. A molecular genetic characterization was performed on tumor tissues and plasma samples. Aberrant $A L K$ expression was detected in 2/12 patients using mRNA purified from plasma specimens and the results agreed with the FISH and immunohistochemistry findings of solid biopsy samples. The detection of aberrant $A L K$ expression on circulating free tumor RNA may be feasible using a one-step real-time PCR assay and may be particularly helpful when a solid biopsy sample is not available.
\end{abstract}

\section{Introduction}

Lung cancer is a major cause of cancer-associated mortality worldwide and targeted therapies represent important agents for the treatment of the disease (1). Therefore, the characterization of molecular alterations of tumors is crucial for identifying patients who are likely to benefit from these types of therapy.

Correspondence to: Professor Gabriella Fontanini, Department of Surgical, Medical, Molecular Pathology and Critical Area, University of Pisa, 57 Via Roma, I-56126 Pisa, Italy

E-mail: gabriella.fontanini@med.unipi.it

Key words: lung adenocarcinoma, ALK rearrangements, circulating free tumor RNA, ALK expression, one-step RT-PCR
Advanced non-small cell lung cancer (NSCLC) patients harboring sensitive epidermal growth factor receptor (EGFR) gene mutations or anaplastic lymphoma kinase $(A L K)$ gene rearrangements can be treated with specific tyrosine kinase inhibitors (TKIs) (2). The incidence of $A L K$ rearrangements in NSCLC is $\sim 3-5 \%$ and they occur more often in never or light ex-smokers, in younger patients and in those with lung adenocarcinoma. Patients exhibiting the $A L K$ gene rearrangement respond well to approved ALK inhibitors, including crizotinib. The most common $A L K$ rearrangement is the echinoderm microtubule associated protein like 4 (EML4)-ALK fusion. This results from an inversion in the short arm of chromosome 2, which causes the fusion of the N-terminal domain of EML4 to the intracellular kinase domain of $A L K$ (3'-gene region), giving a constitutively active ALK tyrosine kinase (3). Tumor tissue is the preferred definitive sample type used for molecular analyses. However, for numerous patients, this type of sample is not available. As a result, the evaluation of surrogate sample types for the molecular characterization of tumors has been gaining increasing interest.

Several studies have already reported the usefulness of circulating free tumor (ct) DNA for the analysis of somatic mutations in NSCLC (4) and the European Medicines Agency approved the assessment of EGFR mutations using ct DNA when tumor tissue is unavailable.

The mRNA has been isolated from plasma, serum, platelets and circulating tumor cells (CTCs) from patients suffering from various types of malignancies, including lung cancer (5-7), and has been used as a biological marker for the early detection and diagnosis, or as a therapeutic and prognostic indicator for the disease $(8,9)$. However, to the best of our knowledge, few studies have reported the use of ct mRNA from serum or plasma to analyze the presence of $A L K$ rearrangements in NSCLC $(10,11)$.

To demonstrate the feasibility of performing a molecular characterization of lung adenocarcinoma using ct nucleic acids, the present study planned a prospective study in which patients with advanced NSCLC were enrolled. The present study reported a series of 12 cases of lung adenocarcinoma tested for aberrant $A L K$ expression on ct mRNA purified 
from plasma and analyzed using a one-step reverse transcription-quantitative polymerase chain reaction (RT-qPCR). Aberrant $A L K$ expression was detected in two patients and the results were confirmed by fluorescence in situ hybridization (FISH) and immunohistochemistry findings of respective solid biopsies. Furthermore, in order to assess the reliability of the present study, ct mRNA from healthy donors and other cancer patients was also tested. Although this is a preliminary study, requiring further confirmation, the present results supported the possibility of detecting $A L K$ aberrant expression on plasma from patients with NSCLC.

\section{Materials and methods}

Patients. Aberrant $A L K$ expression was firstly tested using the mRNA from plasma and formalin-fixed paraffin-embedded (FFPE) tissues from 12 patients with NSCLC (5 male and 7 female; age range, 45-80 years). These patients underwent a bronchial biopsy at the Unit of Thoracic Endoscopy, University Hospital of Pisa (Pisa, Italy) between February and September 2015. All patients belong to a prospective study aiming to evaluate the use of ct nucleic acids for the molecular characterization of lung adenocarcinoma (data not shown). The present study was headed by the Unit of Pathological Anatomy, University Hospital of Pisa and was approved by the local Ethics Committee. Furthermore, $A L K$ expression was analyzed on ct mRNA from the plasma of 4 healthy donors ( 1 male and 3 female; age range, $48-62$ years) and 4 patients with thyroid and colon cancers ( 2 male and 2 female; age range, 42-70 years). This project required the collection of whole blood samples into venous blood collection tubes using ethylenediaminetetraacetic acid tripotassium as an anticoagulant. Written informed consent was obtained from all enrolled patients.

FISH and immunohistochemistry. The diagnosis of lung adenocarcinoma was performed on hematoxylin and eosin stained sections from FFPE lung tissues. FISH was performed using break-apart probes for $A L K$ (Abbott Molecular, Des Plaines, IL, USA). The FISH test was considered positive if $15 \%$ or more of the tumor cells had separate $5^{\prime}$ (green) and 3 (red) probe signals or had isolated 3 ' signals. Overlapping red and green signals (resulting in yellow) indicated cells in which ALK was not rearranged. Immunohistochemical staining of the lesion tissue was performed using a rabbit monoclonal primary anti-ALK antibody (clone D5F3; ready to use; Roche-Ventana Medical Systems, Inc., Tucson, AZ, USA) in combination with an OptiView 3,3'-diaminobenzidine immunohistochemistry detection kit and an OptiView Amplification kit (Ventana Medical Systems, Inc.). All the hematoxylin and eosin staining, FISH and immunohistochemical evaluations were performed by two independent pathologists (Professor Gabriella Fontanini and Dr Greta Alì).

Nucleic acid extraction. Nucleic acids were extracted from FFPE tissues and plasma samples. The DNA and RNA were purified from the FFPE tissues using the QIAamp DNA Mini kit and the RNeasy FFPE kit (Qiagen, Valencia, CA, USA), respectively. The plasma was isolated from whole blood within 2-4 h of sample collection by centrifugation at $1,730 \mathrm{~g}$ for $10 \mathrm{~min}$ at $4^{\circ} \mathrm{C}$. Once isolated, plasma samples were immediately centrifuged again at $12,500 \mathrm{~g}$ for $10 \mathrm{~min}$ at $4^{\circ} \mathrm{C}$ and frozen at $-80^{\circ} \mathrm{C}$ until processing. The isolation of ct DNA and RNA was performed separately from $3 \mathrm{ml}$ plasma using the QIAmp Circulating Nucleic Acid kit (Qiagen). The ct mRNA was then further purified, after a DNase digestion step, using the RNeasyMinElute Clean Up kit (Qiagen). The analyses of solid and liquid biopsy samples were performed independently by different investigators.

Mutational analysis. The mutational status of the tumor tissue and plasma samples were determined by a Sequenom Mass-Array (MALDI-TOF MS) using the Myriapod Lung Status kit (Diatech Pharmacogenetics Srl, Jesi, Italy) together with the analysis software MASSARRAY ${ }^{\circledR}$ TYPER 4.0 (Diatech Pharmacogenetics Srl) (12), which allows the simultaneous genotyping of 307 variants in the EGFR, KRAS, $B R A F, P I K 3 C A, N R A S, A L K, E R B B 2, D D R 2, M A P 2 K 1$ and $R E T$ genes. The analysis of ct DNA was also performed using the more sensitive Easy Real-Time PCR kits (Diatech Pharmacogenetics Srl) for the most common variants of EGFR and KRAS.

ALK expression analysis. The aberrant expression of mRNA encoding for ALK was analyzed using the Easy-ALK kit (Diatech Pharmacogenetics Srl), which uses primers and probes specific for the $A L K$ tyrosine kinase domain. This method is a one-step procedure, during which mRNA molecules are reverse-transcribed and directly amplified for both $A L K$ and a control gene, $\beta$-actin (ACTB). In addition, each experimental run contains a positive transcript control for both $A L K$ and $A C T B$ expression and a negative template control. The analysis was performed on a Rotor-Gene Q PCR thermocycler and analyzed by the Rotor-Gene 6000 Series software (Qiagen). Thermocycling conditions were as follows: $42^{\circ} \mathrm{C}$ for $5 \mathrm{~min} ; 95^{\circ} \mathrm{C}$ for $10 \mathrm{sec}$; 40 cycles of $95^{\circ} \mathrm{C}$ for $5 \mathrm{sec}$ and $60^{\circ} \mathrm{C}$ for $30 \mathrm{sec}$. According to manufacturer's protocol, after the run is completed, sample $\mathrm{Cq}$ values are determined for both $A L K$ (target expression assay) and $A C T B$ (control expression assay). If $A C T B$ amplification is detected, the RNA sample is of good quality and $A L K$ expression can be assessed. If $A C T B$ amplification is absent, the sample was not further evaluated as the quality was not good enough. Under normal conditions, without any rearrangements, $A L K$ expression should not be detectable using this method.

\section{Results}

FISH and immunohistochemistry. The immunohistochemical analysis detected strong granular cytoplasmic expression of the ALK protein only in 2/12 NSCLC enrolled patients. In the two positive cases, now referred to as patient 1 and 2, FISH reported that 68 (34 ALK positive nuclei from 50 examined) and $16 \%$ ( 8 ALK positive nuclei from 50 examined) of the neoplastic cells, respectively, were positive for the EML4-ALK rearrangement, according to the scoring method proposed by Kwak et al (13). Figure 1 presents the hematoxylin and eosin staining sections, immunohistochemistry and FISH images from the two ALK-positive patients. In detail, patient 1 was a 44-year-old African man who never smoked, with a clinical 

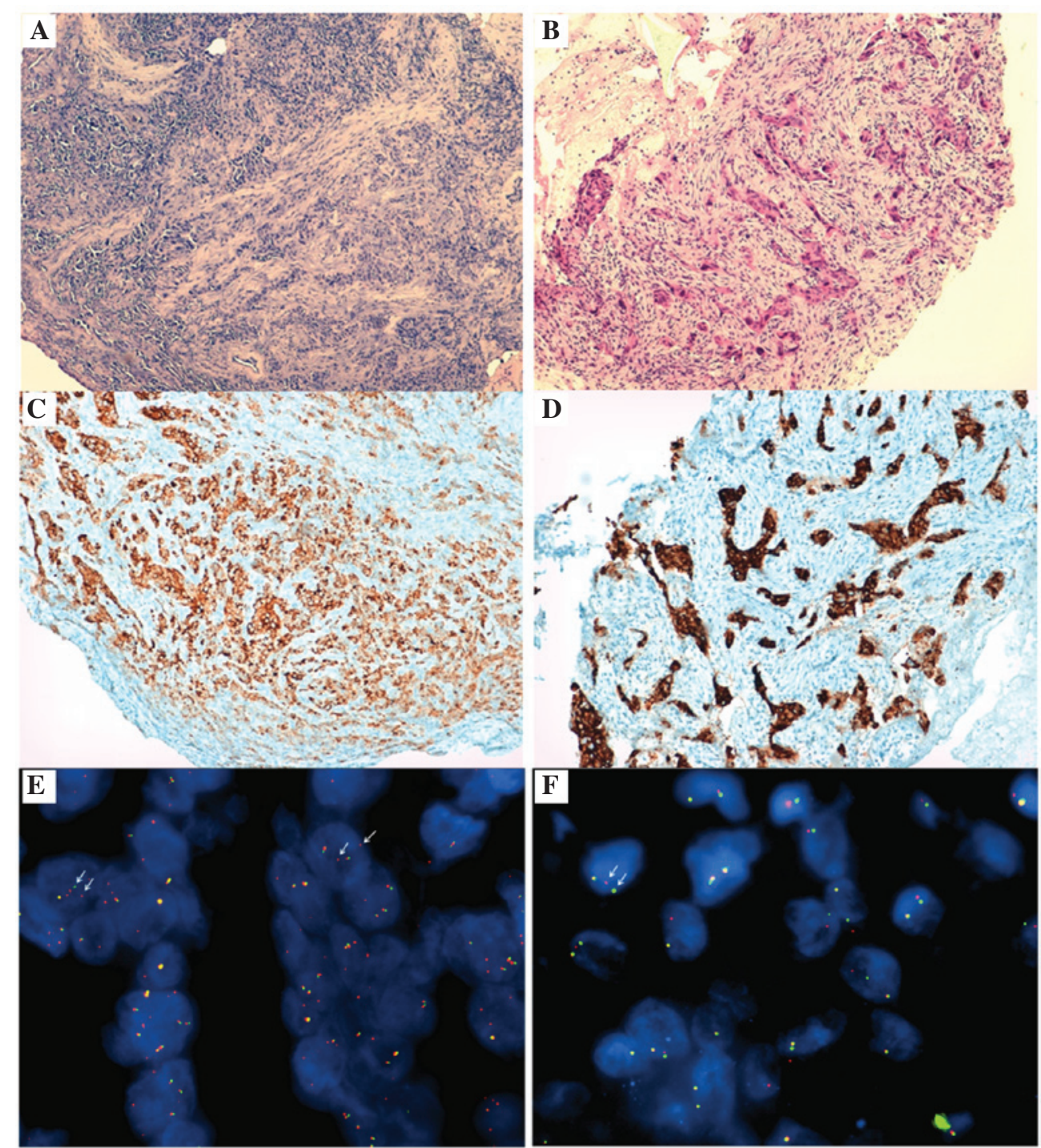

Figure 1. Microscopy analysis of the two cases. (A and B) Hematoxylin and eosin staining (magnification, $\mathrm{x} 10$ ) and (C and D) immunohistochemistry using an antibody against ALK was performed on formalin-fixed paraffin-embedded tissue sections from the two EML4-ALK-positive specimens (magnification, $\mathrm{x} 10)$. (E and F) A fluorescence in situ hybridization analysis of the lung tumor samples highlighted cells with an ALK translocation in patient 1 by two normal signals and two isolated red signals (arrows; magnification, x100) and in patient 2 by one normal (paired) signal and two pairs of separated signals (arrows). Panels A, C and E refer to patient 1, and panels B, D and F refer to patient 2. ALK, anaplastic lymphoma kinase; EML, echinoderm microtubule associated protein-like 4.

diagnosis of cT4N3M1a-b lung adenocarcinoma with tumor metastases involving the liver, bones and brain. Patient 2 was a 57-year-old European woman with a previous history of smoking, with a clinical diagnosis of cT4N3M1a-SIVb lung adenocarcinoma with cerebral and thoracic involvement (data not shown).

Mutational analysis. The mutational analysis of EGFR, KRAS, $B R A F, P I K 3 C A, N R A S, A L K, E R B B 2, D D R 2, M A P 2 K 1$ and $R E T$ genes, on solid and liquid biopsies, revealed that no patient with NSCLC harbored any of the tested mutations in their tumors.

ALK expression analysis. The ct mRNA samples from all the enrolled patients, including the healthy donors and the other cancer patients, exhibited a satisfactory $A C T B$ amplification, confirming their good quality for the evaluation step (data not shown). Patients 1 and 2 exhibited a specific PCR amplification curve in the ALK sample reactions (Fig. 2). None of the other analyzed patients exhibited $A L K$ amplification (data not shown). The gene expression results on ct mRNA were confirmed also on mRNA purified from NSCLC and other cancer type FFPE tissues.

\section{Discussion}

The molecular characterization of ct nucleic acids may be helpful for decision-making for the treatment of patients with NSCLC whenever tumor tissue is not available. The plasma may represent a surrogate source of tumor nucleic acids for both genotyping and gene expression analyses.

The rearranged $A L K$ gene acts as an oncogene in lung adenocarcinoma and it can arise from fusions with several partners, including EML4, HIPI and TPR (14-16). Patients with $A L K$ rearrangements can be successfully treated with ALK inhibitors, including crizotinib $(17,18)$. 

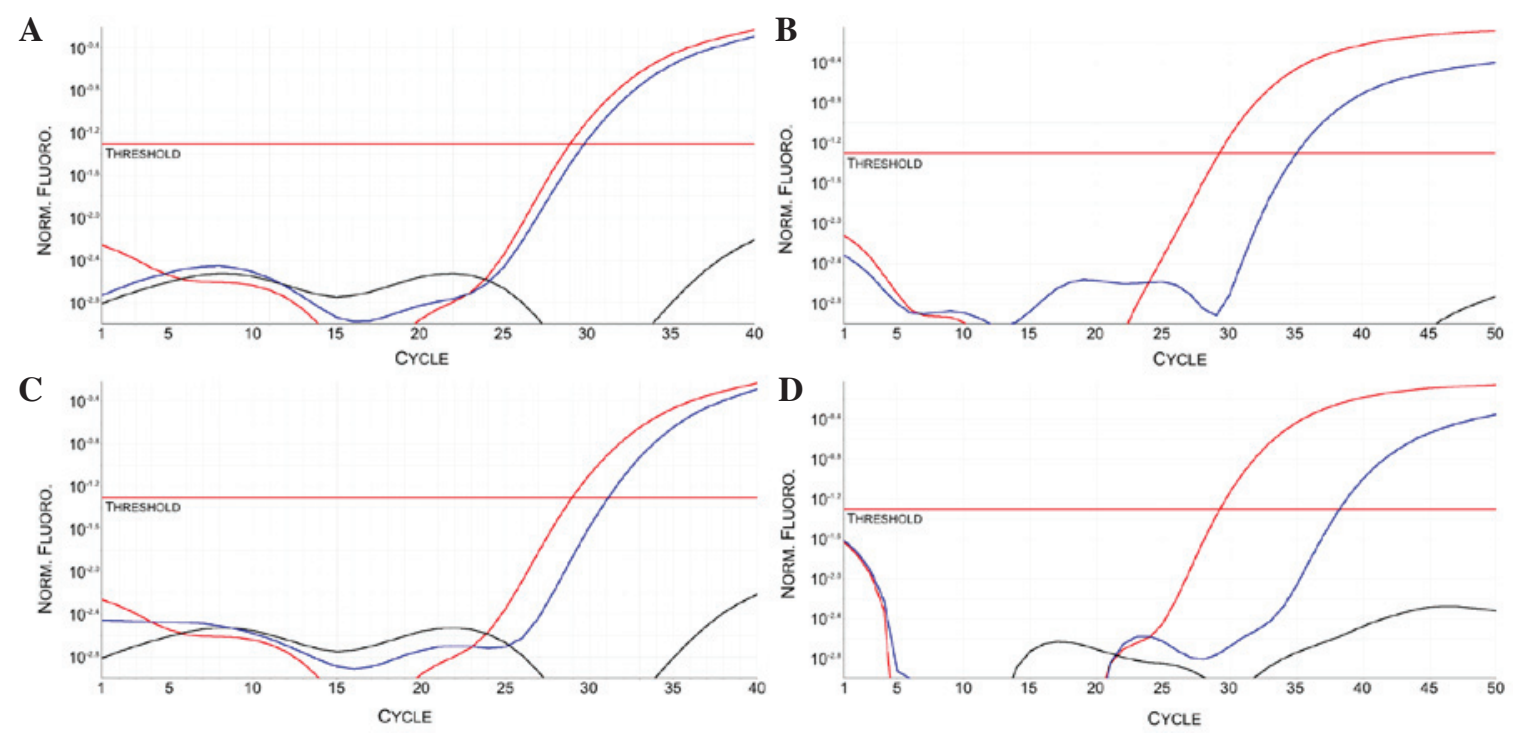

Figure 2. Graphs from the reverse transcription-polymerase chain reaction. Analysis in (A and B) patient 1 and (C and D) patient 2 revealed aberrant anaplastic lymphoma kinase expression detected both in (A and C) tumor tissues and (B and D) circulating free tumor mRNA. The red curve indicates the positive control of synthetic ALK-positive DNA, the blue curve indicates the samples and the black curve is the no template control.

For numerous years, CTCs have been suggested for tumor molecular characterization $(6,7,9)$, however they are very difficult to detect and isolate from normal nucleated cells in the blood, and their clinical use remains limited.

To the best of our knowledge, little is known about the evaluation of aberrant $A L K$ expression in plasma and serum, with the exception of two previous studies, one performed by Kudo et al (10) on serum samples using the MassArray system and one by Nilsson et al (11) on the mRNA from plasma and platelets by RT-PCR. Nilsson et al (11), in particular, assessed the possibility of detecting the three most common EML4-ALK variants on the mRNA from platelets and plasma in patients with NSCLC. The authors used quantitative two-steps PCR TaqMan assays and reported a sensitivity of 21 and $65 \%$ of the RT-PCR test in the plasma and platelets RNA, respectively.

In order to demonstrate the feasibility of evaluating aberrant expression of $A L K$ on lung adenocarcinoma using ct mRNA purified from plasma, the present study analyzed 12 patients with NSCLC and identified $A L K$ rearrangements in two cases. All patients with NSCLC included in the present study belonged to a prospective series of 34 lung adenocarcinoma patients (data not shown). The percentage of $A L K$ rearranged cases in the present study is consistent with the reported incidence of $3-5 \%$ in NSCLC (3).

The described positive patients had 68 and $16 \%$ of neoplastic nuclei positive for $A L K$ rearrangement by FISH, and both were positive for $A L K$ aberrant mRNA expression in plasma by the one-step RT-qPCR technique. Although this method is unable to characterize the specific rearranged $A L K$ variants, the presence of aberrant $A L K$ mRNA levels in plasma samples may be enough to indicate that patients are candidates for TKI-based therapy where tumor biopsies are not available. Notably, when a solid biopsy is not available, it is challenging to determine which of the most common EML4-ALK variants should be analyzed on plasma, since $E M L 4$ is not the only $A L K$ rearrangement partner. In this context, the evaluation of aberrant expression of $A L K$, directly on a small quantity of ct mRNA extracted from few milliliters of plasma, can represent a promising diagnostic tool. Furthermore, the absence of an ALK amplification curve in $A L K$ negative NSCLC patients, healthy donors and other cancers patients, confirmed the specificity of the used primers and probes. Further studies on a larger series of samples are required to confirm this data.

In addition, the detection of aberrant $A L K$ mRNA expression both on tissue and plasma can be useful whenever immunohistochemistry and FISH results are discordant. It has been previously demonstrated that a single FISH or immunohistochemical analysis may not detect all the ALK-positive cases and that certain patients with discordant testing respond to TKIs (19). In several previous studies, the use of RT-PCR for the detection and characterization of specific $A L K$ fusions has been evaluated, and the sensitivity and specificity reported ranged between 94 and $100 \%$ (20-22). However, the clinical application of specific RT-PCR assays has been limited by the number of reactions and the large quantity of clinical samples required to investigate the different $A L K$ fusions. Previously, Huang et al (23) demonstrated, both on NSCLC tissue samples and on cell-free urine samples, the efficacy of a differential expression method, based on the presence of aberrant high levels of the $A L K$ kinase domain (23). Notably, the predominant pathological consequence of $A L K$ fusion in tumor cells is its aberrant expression, regardless of the fusion partner. Similarly, the one step method used in this work can be applied to evaluate the presence of aberrant expression levels of $A L K$.

Furthermore, in lung adenocarcinoma, $A L K$-rearrangements showed a considerable level of intratumoral heterogeneity, which can influence the assessment and the success of therapies (24). The evaluation of aberrant $A L K$ expression on ct RNA may be a powerful tool to implement tumor characterization on solid biopsy for primary screening and predominantly to monitor the disease progression. 
Despite the relatively unstable nature of mRNA, particularly from the plasma, the present study confirmed that $\mathrm{ct}$ mRNA is suitable for RT-qPCR, according to Nilsson et al (11). However, to obtain good quality mRNA for the amplification step, the optimization of sampling phases and nucleic acid purification is urgently required, and a one-step RT-PCR assay may be recommended to reduce the bias associated with a distinct retrotranscription step.

Currently, no ALK RT-qPCR kits have been confirmed on liquid biopsies; therefore, the present study used the same of FFPE tissues and obtained satisfying results for all the analyzed samples, since all showed a good amplification of the $A C T B$ control gene.

The present study represented a starting point for further research on a larger number of patients to define the sensitivity and specificity of this detection system, and to delineate a specific protocol for plasma samples that can be included in routine clinical practice for NSCLC. This would be particularly helpful for when a solid biopsy is not available. The analysis of ct nucleic acids may include not only characterization of the mutational status of the EGFR, but also detection of aberrant $A L K$ expression.

\section{References}

1. Siegel R, Ma J, Zou Z and Jemal A: Cancer statistics, 2014. CA Cancer J Clin 64: 9-29, 2014.

2. Rekhtman N, Leighl NB and Somerfield MR: Molecular testing for selection of patients with lung cancer for epidermal growth factor receptor and anaplastic lymphoma kinase tyrosine kinase inhibitors: American society of clinical oncology endorsement of the college of American pathologists/international association for the study of lung cancer/association for molecular pathology guideline. J Oncol Pract 11: 135-136, 2015.

3. Solomon B, Varella-Garcia M and Camidge DR: ALK gene rearrangements: A new therapeutic target in a molecularly defined subset of non-small cell lung cancer. J Thorac Oncol 4: 1450-1454, 2009.

4. Douillard JY, Ostoros G, Cobo M, Ciuleanu T, Cole R, McWalter G, Walker J, Dearden S, Webster A, Milenkova T and McCormack R: Gefitinib treatment in EGFR mutated caucasian NSCLC: Circulating-free tumor DNA as a surrogate for determination of EGFR status. J Thorac Oncol 9: 1345-1353, 2014.

5. Schmidt B, Engel E, Carstensen T, Weickmann S, John M, Witt C and Fleischhacker M: Quantification of free RNA in serum and bronchial lavage: A new diagnostic tool in lung cancer detection? Lung Cancer 48: 145-147, 2005.

6. Ross K, Pailler E, Faugeroux V, Taylor M, Oulhen M, Auger N, Planchard D, Soria JC, Lindsay CR, Besse B et al: The potential diagnostic power of circulating tumorcell analysis for non-small-cell lung cancer. Expert Rev Mol Diagn 13: 1605-1629, 2015.

7. Pailler E, Adam J, Barthélémy A, Oulhen M, Auger N, Valent A, Borget I, Planchard D, Taylor M, André F, et al: Detection of circulating tumor cells harboring a unique ALK rearrangement in ALK-positive non-small-cell lung cancer. J ClinOncol 31: 2273-2281, 2013.

8. Schwarzenbach $\mathrm{H}$, Hoon DS and Pantel K: Cell-free nucleic acids as biomarkers in cancer patients. Nat Rev Cancer 11: 426-437, 2011.
9. Faugeroux V, Pailler E, Auger N, Taylor M and Farace F: Clinical utility of circulating tumor cells in ALK-positive non-small-cell lung cancer. Front Oncol 4: 281, 2014.

10. Kudo K, Nishio M, Sakai K, Tanimoto A, Sakatani T and Saito R: Detection of EML4-ALK in serum RNA from lung cancer patients using MassARRAY platform. J Clin Oncol 30 (suppl; abstr 10569), 2012.

11. Nilsson RJ, Karachaliou N, Berenguer J, Gimenez-Capitan A, Schellen P, Teixido C, Tannous J, Kuiper JL, Drees E, Grabowska M, et al: Rearranged EML4-ALK fusion transcripts sequester in circulating blood platelets and enable blood-based crizotinib response monitoring in non-small-cell lung cancer. Oncotarget 7: 1066-1075, 2016.

12. Gabriel S, Ziaugra L and Tabbaa D: SNP genotyping using the Sequenom MassARRAY iPLEX platform. Curr Protocs Human Genet: Chapter 2: Unit 2.12, 2009.

13. Kwak EL, Bang YJ, Camidge DR, Shaw AT, Solomon B, Maki RG, Ou SH, Dezube BJ, Jänne PA, Costa DB, et al: Anaplastic lymphoma kinase inhibition in non-small-cell lung cancer. N Engl J Med 363: 1693-1703, 2010.

14. Soda M, Choi YL, Enomoto M, Takada S, Yamashita Y, Ishikawa S, Fujiwara S, Watanabe H, Kurashina K, Hatanaka $\mathrm{H}$, et al: Identification of the transforming EML4-ALK fusion gene in non-small-cell lung cancer. Nature 448: 561-566, 2007.

15. Hong M, Kim RN, Song JY, Choi SJ, Oh E, Lira ME, Mao M, Takeuchi K, Han J, Kim J and Choi YL: HIP1-ALK, a novel fusion protein identified in lung adenocarcinoma. J Thorac Oncol 9: 419-422, 2014.

16. Choi YL, Lira ME, Hong M, Kim RN, Choi SJ, Song JY, Pandy K, Mann DL, Stahl JA, Peckham HE, et al: A novel fusion of TPR and ALK in lung adenocarcinoma. J Thorac Oncol 9: 563-566, 2014.

17. Shaw AT, Kim DW, Nakagawa K, Seto T, Crinó L, Ahn MJ, De Pas T, Besse B, Solomon BJ, Blackhall F, et al: Crizotinib versus chemotherapy in advanced ALK-positive lung cancer. N Engl J Med 368: 2385-2394, 2013.

18. Cameron L and Solomon B: Treatment of ALK-rearranged non-small cell lung cancer: Recent progress and future directions. Drugs 75: 1059-1070, 2015.

19. Cabillic F, Gros A, Dugay F, Begueret H, Mesturoux L, Chiforeanu DC, Dufrenot L, Jauffret V, Dachary D, Corre R, et al: Parallel FISH and immunohistochemical studies of ALK status in 3244 non-small-cell lung cancers reveal major discordances. J Thorac Oncol 9: 295-306, 2014.

20. Pan Y, Zhang Y, Li Y, Hu H, Wang L, Li H, Wang R, Ye T, Luo X, Zhang Y, et al: ALK, ROS1 and RET fusions in 1139 lung adenocarcinomas: A comprehensive study of common and fusion pattern-specific clinicopathologic, histologic and cytologic features. Lung Cancer 84: 121-126, 2014.

21. Takeuchi K, Choi YL, Soda M, Inamura K, Togashi Y, Hatano S, Enomoto M, Takada S, Yamashita Y, Satoh Y, et al: Multiplex reverse transcription-PCR screening for EML4-ALK fusion transcripts. Clin Cancer Res 14: 6618-6624, 2008.

22. Soda M, Isobe K, Inoue A, Maemondo M, Oizumi S, Fujita Y, Gemma A, Yamashita Y, Ueno T, Takeuchi K, et al: A prospective PCR-based screening for the EML4-ALK oncogene in non-small cell lung cancer. Clin Cancer Res 18: 5682-5689, 2012.

23. Huang Q, Deng Q, Jiang L, Fang R, Qiu Y, Wang P, Zhou JX and Yang H: Assessment of ALK gene fusions in lung cancer using the differential expression and exon integrity methods. Oncol Lett 11: 1651-1656, 2016.

24. Zito Marino F, Liguori G, Aquino G, La Mantia E, Bosari S, Ferrero S, Rosso L, Gaudioso G, De Rosa N, Scrima M, et al: Intratumor heterogeneity of ALK-rearrangements and homogeneity of EGFR-mutations in mixed lung adenocarcinoma. PLoS One 10: e0141521, 2015. 